\title{
THE . TUBE SKIN-FLAP IN PLASTIC SURGERY 321
}

\section{THE TUBE SKIN-FLAP IN PLASTIC SURGERY.}

\author{
Bi H. P. PICKkRIII. axd J. Renfrew White, Denedix, New Zealand.
}

'TuE exact origin of the 'tube-flap' is difficult to trace. Many unlined flat flaps, if they lived, converted themselves into tube-flaps by reason of the cicatricial contraction which resulted on their under surfaces. This may have originated the observation that if a long flap did not die it became a tube, and conversely, that a tubed flap would be more viable than a flat flap. (See Fig. 324.) It does not, however, seem to have attracted any particular notice, since no text-books mention it. The kinemato-plastic flaps of Vanghetti and Putti depend for their viability and usefulness upon the adoption of the tube form, although these authors do not draw attention to this fact.

The tube-flap probably was first extensively used as a means of maintaining the nourishment of large flaps at the Queen's Hospital, Sidcup, during the war, when it was extensively employed by Major Gillies, Major Waldron, Lieutenant-Colonel Newland, and one of the writers (H. P. P.). It was then chiefly used for the purpose of conveying tissues from the chest or low down on the neck to some part of the face, with extraordinarily satisfactory results. The tube-flap and tube-graft are, however, capable of considerable extension of usefulness, and it is with the object of calling attention to this aspect that the present communication is made.

\section{THE TUBE-FLAP AND THE TUBE-GRAFT IN FACIAL SURGERY.}

By H. P. Pickerili.

The tube-flap in plastic facial surgery is used to convey tissue to the face from the chest, neck, scalp or forehead in a viable condition. It has the obvious advantagebesides that of almost certain vitality - of avoiding additional scars on the face; in fact so great an advantage is this that the author has now almost entirely abandoned the practice of cutting flaps from one part of the face to remedy a loss or defect of some other part of the face. So far as present observations go, the limit of length of such tube-flaps has not been reached. (Figs. 327, 328, 329).

Technique of the Operation.-A neck tube-flap is fashioned as follows :--.-

1. Two parallel incisions are made along the line of the sternomastoid about 2 inches: apart. The skin, subcutaneous tissue, and platysma are then dissected off the sternomastoid, thus forming a broad flat flap. The two edges of the flap are now brought together, with the skin surface outwards, and sutured accurately, thus forming a 'tube'. 'The skin margins of the wound are then freely undermined and brought together, leaving the 'tube' hanging free for the greater part of its length, but united to the neck at its upper and lower ends (Fig. 310).

The author prefers in this class of tube-i.e., where there is no direct arterial supply or venous return-to leave it for ten days or a fortnight until the margins have well united before swinging it up on to the face. By this procedure the possibility of the introduction of sepsis into the length of the tube is considerably lessened (Fig. 311). This of course is a most important point, since any serious sepsis in the substance of the tube, if it extends across its whole diameter, is almost equal to dividing it with a knife as far as the vitality of the free end of the graft is concerned.

2. The lower end of the tube, with or without any additional flat flap, is divided, swung up to the face, and inserted accurately in its prepared bed (Fig. 312).

VOL. IX. - NO. 35 . 
3. At the end of ten days the tube is divided at its distal end and opened out flat again. The sear in the neck is excised and the flap reinserted into the neck; thus the only tissue ultimately lost from the neck is from the lower end near or below the clavicle.

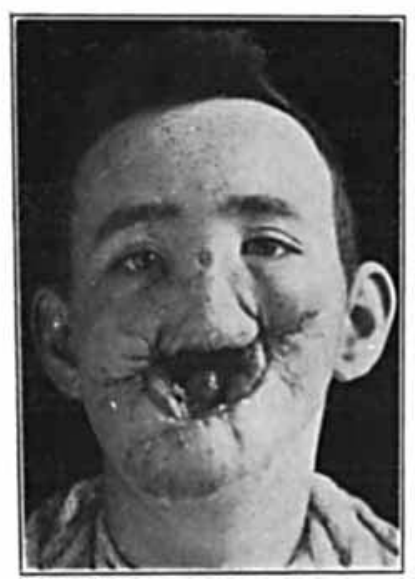

FII. 809.

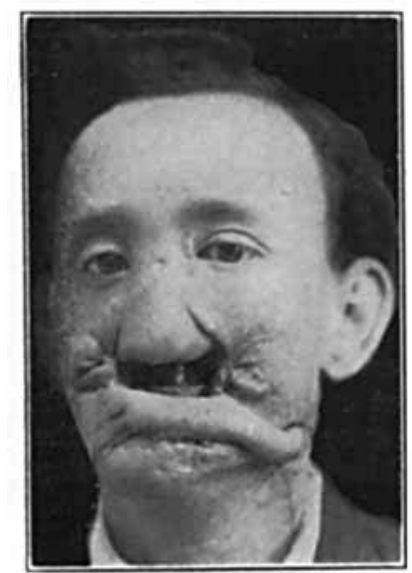

Firi. 312 .

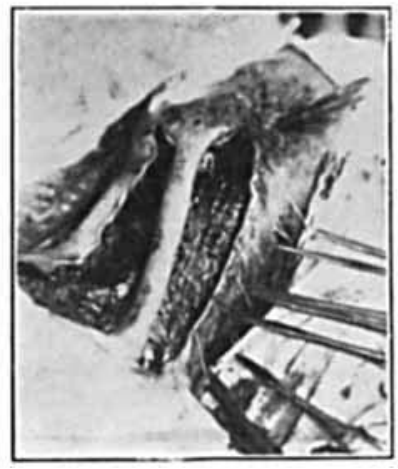

Fiti. 310.

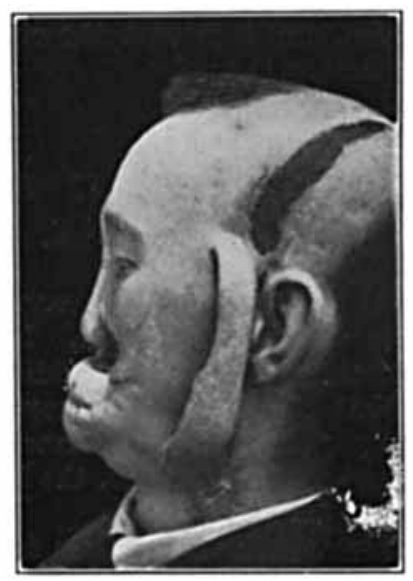

FIt. 813.

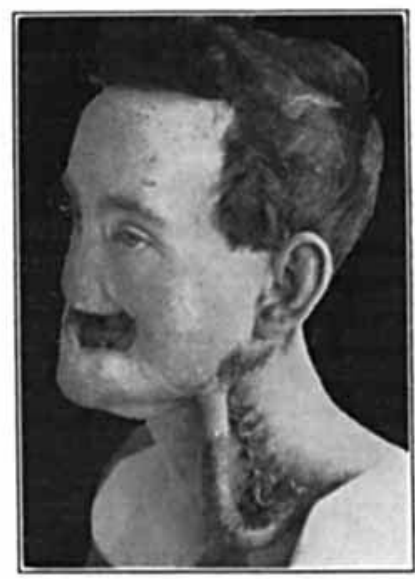

FIG. 311.

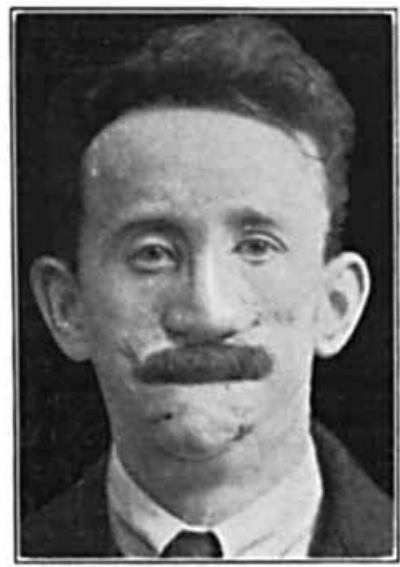

Fili. 314.

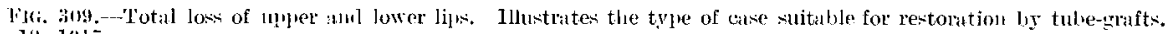
A11\%. $18,191 \%$

Fri. 310 . Flow esther a tuhe-1lat or tube-graft in process of formation from the neck.

Fifi, 311. Thbe-flap formed from the lleck, hanging free except for attachment at both eids. It remaims thum for ten days, when it: lower end is divided and the graft swung into the desired position.

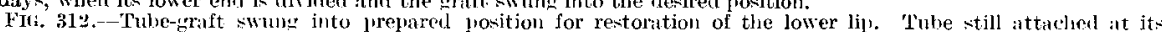
10sterior ent.

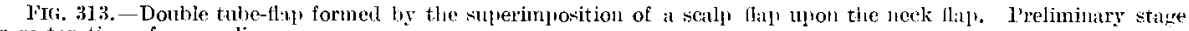
for restoration of upper lip.

The netk flap (1erived from whit was not required for the restorntion of the lower lin) servex as an artificjal mucous membrane, and the sculp flep as the onter skin of the upper ljp, thin enabling the patient to trow il moustache if clesired.

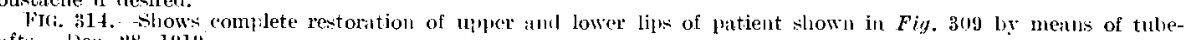
trit tis. Dec. $2 x, 191 ! 1$

'This area, if large, can always be skin-grafted, and in any case is in a favourable situation (Fig. 320).

4. 'Caterpillar' grafts. Should the tube not be long enough for its original intention (indeed it may sometimes with advantage be purposely made short), it may be 'cater- 


\section{THE TUBE SKIN-FLAP IN PLASTIC SURGERY}

pillared into place. To accomplish this, the lower end of the tube is divided, swung upwards, and inserted into a small prepared bed as high up as possible. At the end of ten days this process is repeated. The lower (original proximal) end being divided, swung up, and in turn inserted in a small prepared bed - and so on until the desired situation is reached (Fig. 315).

Small adventitious blood-vessels develop into the ends of such "caterpillared" tubes with astonishing rapidity. A certain allowance has to be made for shrinkage in length of all tube-grafts, but given absolute asepsis, this should not amount to more than onesixth.

A similar technique is employed with tube-grafts in other situations, except that where there is an assured blood-supply the tube may be made and the flap brought into position at one operation. For instance, in a lateral temporal or parietal tube-flap containing branches of the superficial temporary artery and vein, the tube and flap may be at once cut, formed, and swung into position on the nose or chin, as the case may be, without any fear of loss of vitality of the distal end of the flap (Figs. 316 and 317).

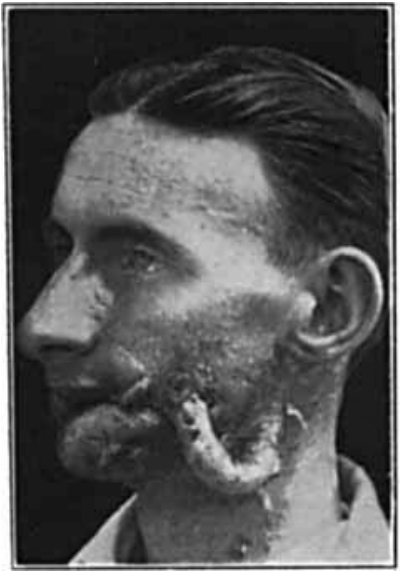

FIG, 315,

Fu: 315. 'Catcriblar' tube-1rait from neek for restonation of lower lijt.

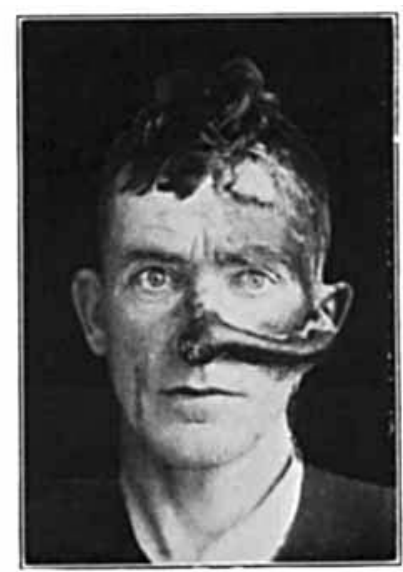

Frri. 316;

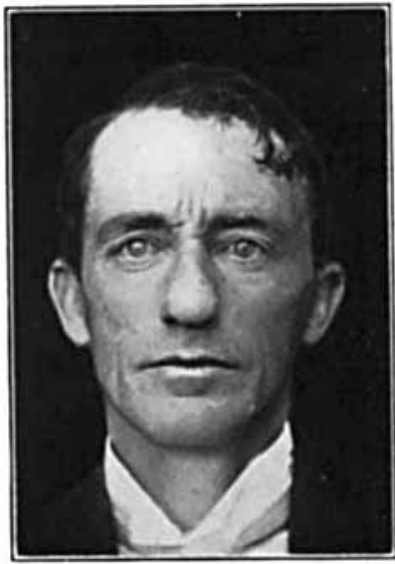

Fli. $31 \bar{t}$

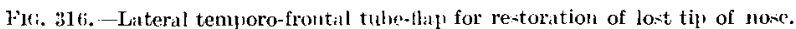
This lap, containing the anterior branch of the superficial temporal artery, can be brourht down jmmediately into the desireal position. It haw a very ligh vitality. ('llotorraph taken after the application of jolline.) Sept. $25,1919$.

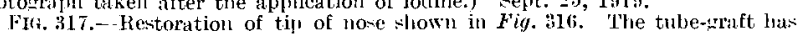

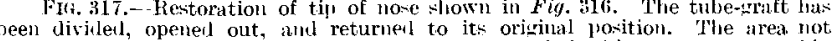

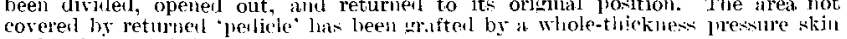
urtet. Vos. $7 ; 1919$.

The Tube-graft. - This name may be applied to a variation of the tube-flap when the tube form is itself used for the graft and not merely as a carrier of nourishment (Figs. 312 and 315).

Such tube-grafts are particularly useful in the restoration of lips and the repair of palatal defects, or any similar situation. The technique of the operation is the same except that the tube is allowed to "hang" for at least a fortnight, by when it becomes slightly congested and acquires a rose flush, which, when it is grafted into position to form a lip, it never loses. Ineredible as it may appear, it is nevertheless quite true that it is very difficult to tell afterwards which is the mucous membrane lip and which skin.

For palatal defects the margins and posterior end of the defect are pared, and the tube split along each side and sutured into position accurately. At the end of a fortnight the tube is divided, and sutures are inserted along the anterior margin of the defect. The lower and unwanted portion of the tube is returned to the neck (Figs. 221, 322, 3223). 


\section{THE BRITISH JOURNAL OF SURGERY}

There is occasionally a tendency to scar formation along the margins of the returned flap; but this I am satisfied is due to too early movement of the neck by the patient, and may be entirely obviated by the use of plaster bandages.

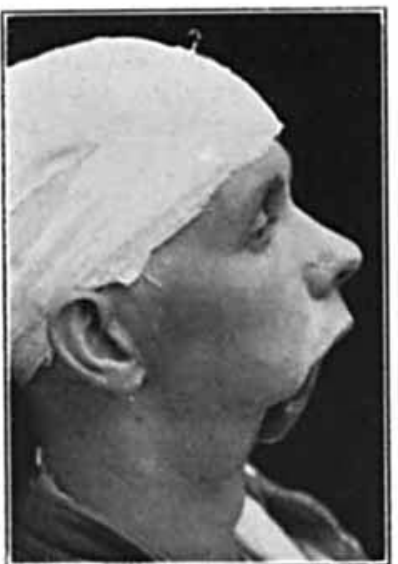

FIf. 318 .

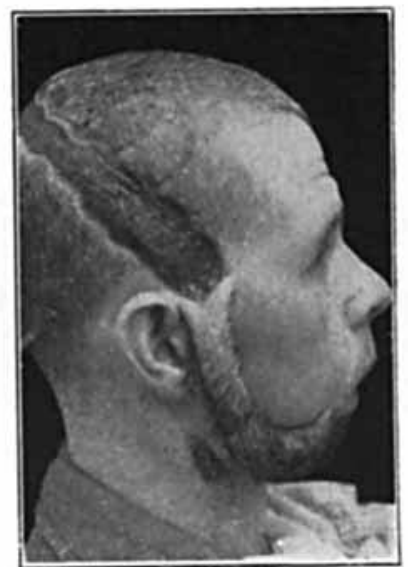

FTt. 319.

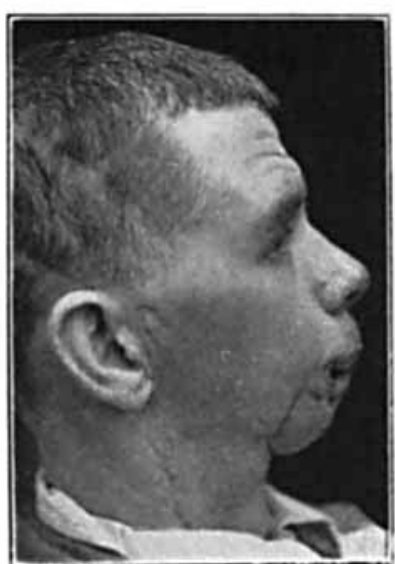

FII, 320.

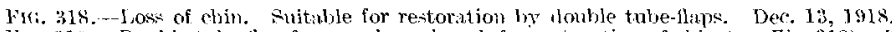

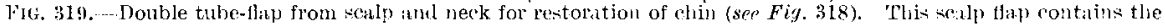

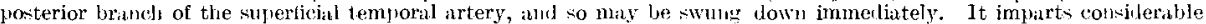
vitality to the underl ring neck tube-llan.

Fil. 320).... How the complete restoration of chin (cf., Fig. :318). The tube-1lap pedieles, as can be seen, hase been opened ont and retumed to their respective previous positions. Mlawh

Aovantages.-Smooth skin inside the mouth, hair-bearing skin outside, and no additional scarring or tension of the face or ncck.

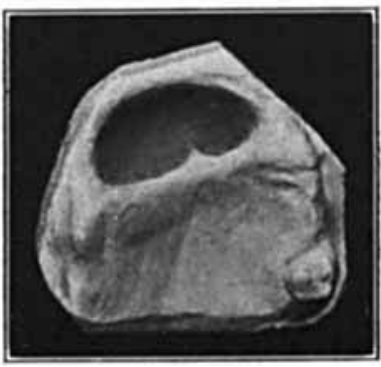

FII, 321,

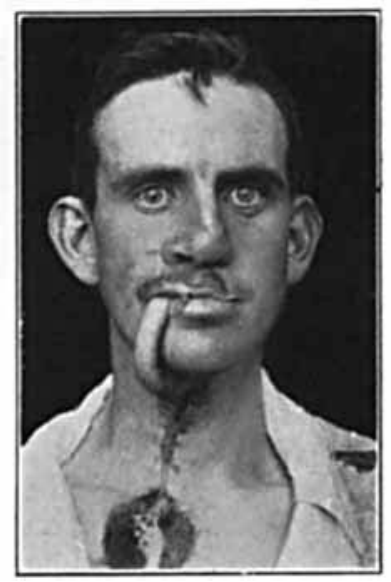

FIG, 322.

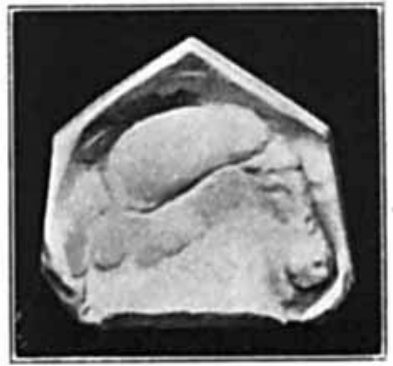

FIG. 323 .

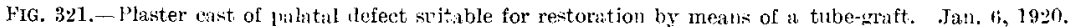

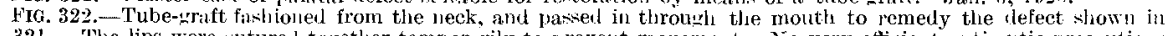
Fin. 321. The lips were sutured torether temporarily to prevent movement. No very efficient antiseptie preculions wore possible, yet the wraft 'took' perfectly. Jan. 23,1920 .

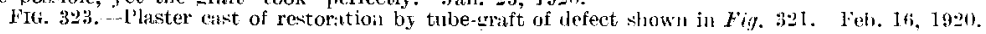

The Double Tube-flap.--This is a modification which is particularly useful in chin and cheek restorations, or in the closure of any hollow viscus which requires an epithelial lining. It consists essentially of a tube-flap of plain smooth skin formed from the neck, swung upwards, and adapted to the defect with its skin surface inwards towards the mouth and its raw surface outwards. Immediately, and at the same operation of course, another tube-flap is fashioned from elsewhere-the scalp, for instance-and turned down to lie 


\section{THE TUBE SKIN-FLAP IN PLASTIC SURGERY}

over the first flap, to which it is accurately adapted. Ten days afterwards both tubes are divided, and returned to their respective original positions.

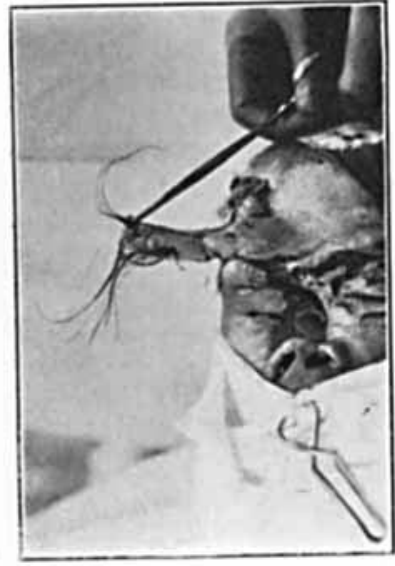

FIG. 324

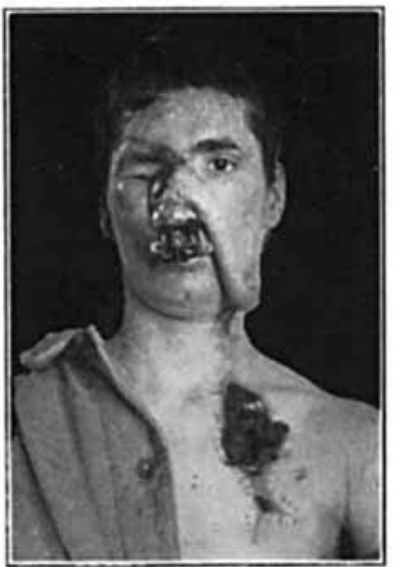

Tig. 325.

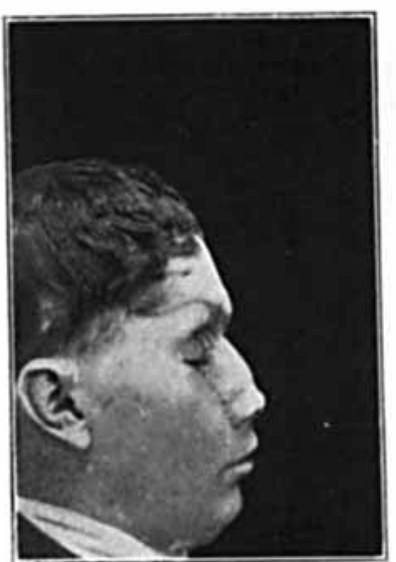

IIG. 326.

lifi. 324.- An unlined rhinoplastic flap which had become detached from the marins of the nasal cavity, and had converted itcelf into a "tube". This tube was opened out, and returned to its original position on the forelie ud. The

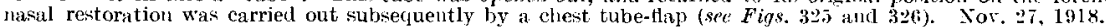

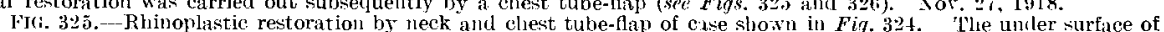
the chest flup was skin-rrafted before being swung up into position, in order to have an epithelial lining on the internal nasal surface.

litG. 3:6.- Rhinoplastic restoration by means of neck-chest tube. Tube pedicle divided, and retırıed to neck, leaving tissue imported from chest in sifu on nose. March $14,1919$.

There remains to repair the defect a complete island of tissues imported from two situations at a considerable distance, lined by smooth hairless skin on the inside and by hairbearing skin on the outside (Figs. $318,319,320$ ).

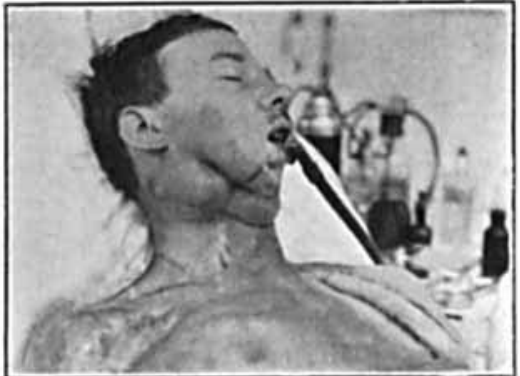

FIti. 327.

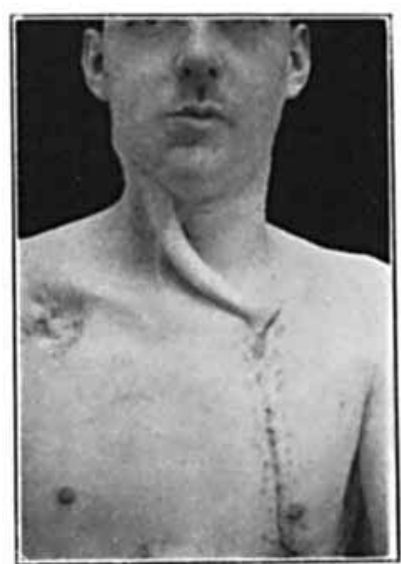

FIG, 38,

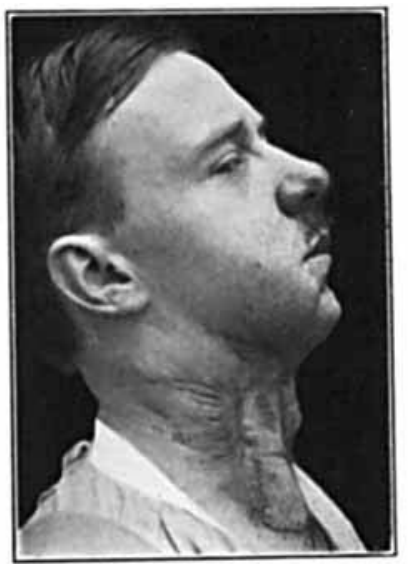

Fici. 329.

FJa, 327.--Tube-flap formed on left sile of chest for renlacing keloid sear on right sille of neck. The keloid hail been removed several times, and ratlium had been applied withont success. The tube conld not be formed on the rirlit side owint to the position of a larese sar on the right sloulder. Jan. $4,1919$.

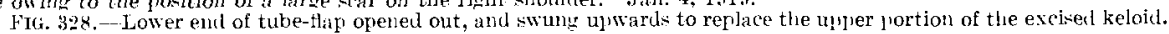
leb. 2,1919 .

Fif. 329.-Original upper ent of tube-thap shown in Fig. 327 divided, onened out. and swung across to rephace the lower portion of the keloid kcar. (l'hotorraph taken soon aftre removal of stitches and before mastare had softelred the flap.) Marcl 4, 1919.

A similar method to this would be of considerable advantage in dealing with such defects as ectopia vesicæ. 
Previous to devising the double tube-flap, it was customary to obtain a lining in chin and cheek losses by turning up a flat flap from the neck in the immediate vicinity of the loss, the 'hinge' of the flap being the lower margin of the defect. This had the obvious disadvantage in men of employing a hair-bearing surface inside the mouth, which proved exceedingly disagreeable and annoying to the patient. It was the undesirability of this procedure which led the writer to devise the tube-graft and the double tube-flap for such cases.

Viability of Tube-flaps. - The extraordinary effect that tubing a flap has on its vitality is evidenced by the fact that, after tubing, a flap may be grafted into a septic cavity like the mouth or nose, or on to a septic surface (chronic ulcers) with almost a certainty of its survival (Figs. 321, 322, 323). This has suggested that after the removal of malignant growths from the face or jaws the loss should, when practicable, be immediately made good, or the raw area grafted by a tubed flap, with the idea of $(a)$ minimizing sepsis, $(b)$ preventing contraction, $(c)$ bringing up an additional blood-supply and fresh tissue from an area not liable to such lesions.

The author is at present utilizing this method, and hopes to make it the subject of a further communication.

\section{THE USE OF THE TUBED-PEDICLED SKIN-GRAFT IN THE SURGERY OF THE LIMBS.}

By J. Renfrew White.

So far as the writer knows, the method of importing skin-flaps from a distance by means of the tubed-pedicled skin-graft has been used up to the present only in the plastic repair of facial injuries and diseases. Invented by the surgeons working at the Queen's Hospital for Facial Injuries at Sidcup, it was first brought to the notice of the writer by the brilliant results obtained in the cases of facial injury among New Zealand soldiers treated by Lieutenant-Colonel H. P. Pickerill, N.Z.M.C., the New Zealand surgeon at Sidcup.

The writer was at once struck by the possibilities of this form of skin grafting; the ease and certainty with which the importation of large areas of normal skin to fill extensive skin defects could be carried out from so great a distance from the face as the neck, the top of the scalp, or the front of the chest - as exemplified by Colonel Pickerill's work -stimulated the writer to experiment with this method in the case of large skin defects and ulcers of the limbs.

Opportunities for these experiments were far from lacking; like every other surgeon engaged in treating orthopædic cases among the wounded, the writer had experience of numerous cases in which the destruction of a considerable area of skin in the limbs had led to the formation of chronic traumatic ulcers with hard indurated circumference and base, ulcers that could only be coaxed into healing with the greatest difficulty or that had defied all forms of treatment, including the usual methods of skin grafting. It seemed to the writer that if this new method of importing healthy skin from a distance could be made applicable to such cases the problem of healing them would be solved.

At the outset it was apparent, however, that there were important differences between the use of this method in the facial cases and its possible use in these cases of chronic ulceration. In the first place, it seemed doubtful whether skin tubes cut from the limbs would be able to develop so good a blood-supply as those cut from skin so richly vascular as that of the scalp and the neck; were it for this reason found impossible to cut long tubes that would remain viable, this would necessitate such a reduction in the length of the tubed pedicle that it would be impossible to transplant skin over the necessary distance-for instance, from the inside of one leg to the inner or outer aspect of the other. A further important difference lay in the fact that the facial surgcons who used this method had always transplanted the skin-flaps on to ciean aseptic surfaces to 


\section{THE TUBE SKIN-FLAP IN PLASTIC SURGERY}

which the imported skin had at once adhered and from which it very soon derived an additional supply of blood; whereas it was to effect the healing of chronically infected discharging ulcers that the writer proposed to try this method.

It seemed reasonable to suppose-what subsequent experience proved to be truethat it would take a much longer and, in different cases, a very variable period for the imported pedicle flap to adhere to the infected surface and to gain from it a blood-supply sufficient to ensure its survival after the division of its pedicle.

Despite some early failures, which, with fuller knowledge and experience, the writer feels confident he could now avoid, the experiments have had so gratifying a measurc of success that he has determined to publish an account of the technique and results of this method of obtaining certain and permanent healing in a class of case that has hitherto been notorious for the difficulty and uncertainty of its cure.

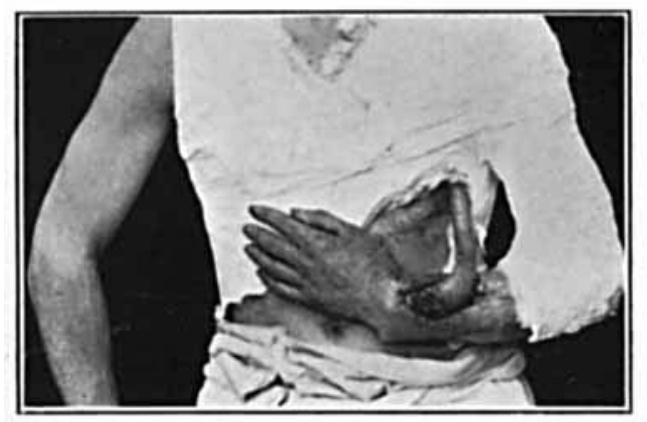

FIr:. 330 .

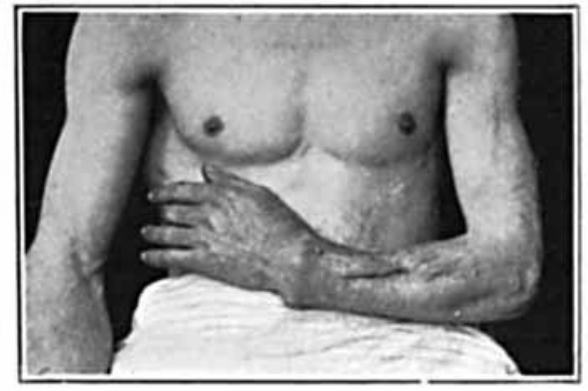

F!r. 381 .

FI(i. 330.-This shows the result of the second state in the trentme it of a chronic carity in the lower emt of the ratius, the end-resuit of a year-old process of osteomyelitis. No tisile could be obtained lowilly to fill this civity: a harge skit

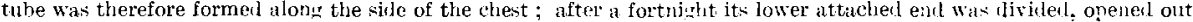
ind sutured into position so as to fill the cavity.

Fin. 331.- The final stane of this plastic clowure of the osteomyclitic carity in the lower end of the ralliw.

This photograph was taken one year after that of $F$ il. 331. The cavity las remainet healed all this time. It was found necessary to $w_{\text {in }}$ th thee weeks in this case before diviling the tubed peclicle, as it took all that time for the imploctel

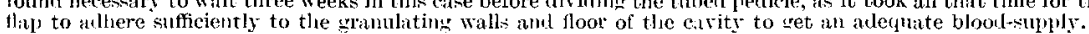

Why these chronic ulcers refuse to heal spontaneously.-Chronic ulcers of the limbs, whether purely traumatic in origin, representing the unhealed remnant of an originally large tissue loss, whether the result of a lowered vitality of the skin of the limb as a whole as in varicose veins, or whether tuberculous in nature as in Bazin's disease, have always been the despair of surgeons. Not only is the obtaining of complete healing a long, tedious, and uncertain process, but when at last they are healed, relapse with recurrence of the ulceration follows sooner or later in many cases.

Failure of spontaneous healing of chronic ulcers is surely in large part at least, if not principally, due to the existence around the periphery and in their base of a thick layer of dense scar tissue, the product of the long-drawn-out inflammatory reaction that represents the effort of the tissues to repair the defect. The cicatricial contraction of this scar tissue has led to a progressive increase in its density with a corresponding decrease in its vascularity, and so has resulted in a reduction of the blood-supply to the granulation tissue and epithelial cells seeking by their proliferation to repair the stillexisting gap. Such interference with the only source of nutrition that these cells possess must limit their active proliferation, must in some cases even render them incapable of resisting the action of the germs still present and active on the surface of the wound, and so must bring to a standstill the tissues' effort at complete repair. 'Thus it would seem to be true that healing of the last part of the wound is prevented by the premature cicatrization of the part already healed. Such seems to the writer the pathological explanation of the chronicity of these lesions. 


\section{THE BRITISH JOURNAL OF SURGERY}

Under such circumstances what is required to bring about healing is some form of surgical interference that will in the first place remove this obstructing layer of accumulated scar, and, in the second, import into the gap so made a flap of normal healthy skin possessing a temporary independent blood-supply of its own so that when the flap has taken, has adhered to the granulating surface, and its pedicle has been cut, the skin defect will be completely made good and the ulcer healed in a stable manner. This means, then, the transplantation on to the freshly granulating surface of a flap of healthy skin of normal thickness, a flap which will ultimately derive its blood-supply, not precariously through a layer of dense contracting scar tissue, but from a healthy vascular granulating surface. This constitutes the ideal form of the healing of these ulcers"; the grafting of normal healthy skin on to the freshly excised surface of the ulcer, with the development of a minimum amount of scar tissue between the skin surface and the subjacent healthy tissues.

The writer considers that this method of treating varicose ulcers (Figs. 338, 339) will give results infinitely superior in certainty, rapidity, and stability of healing to those obtained by any other method that has so far been used.

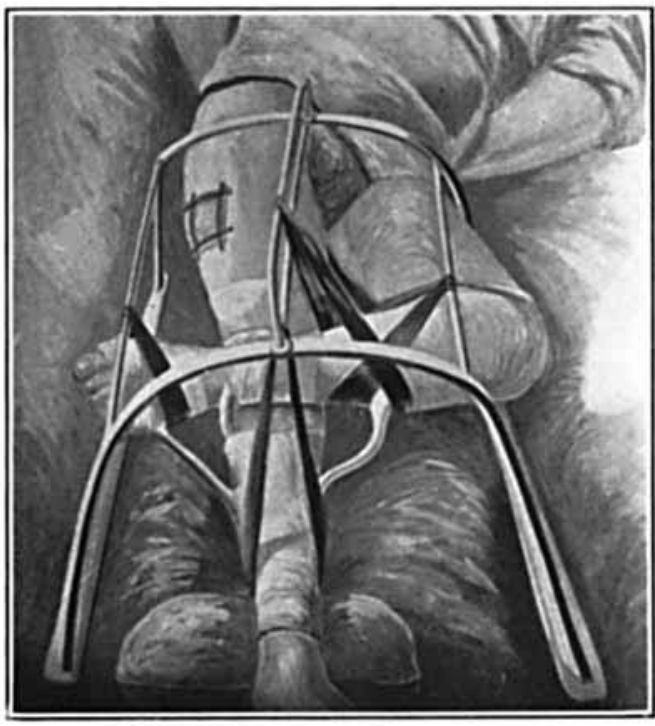

Fit. 332.- Photograph of a sketch of the second stage in the treatment of a chronic ulcer of the lower part of the les, wh ulcer that had persisted unhealed for over a year after a compound fracture of the tibia and fibula. The first stane of the treatment consisted in the formation of a skin tube along the outer aspect of the thigh of the opmosite side just above the outer aspect of the thigh of the opposite side just above the knee. At the second operation the 1lpper end of the tube was cut, opened out, and sutured to the ulcer so as to till the defect completcly. The two limbs were immobilized in the rosition
shown. Hor final result, ser Fig. 333.

The writer considers that this iderl pathological termination-full thickness of normal skin covering healthy vascular tissue with an absolute minimum of scar tissuc between - can in many cases be realized only by means

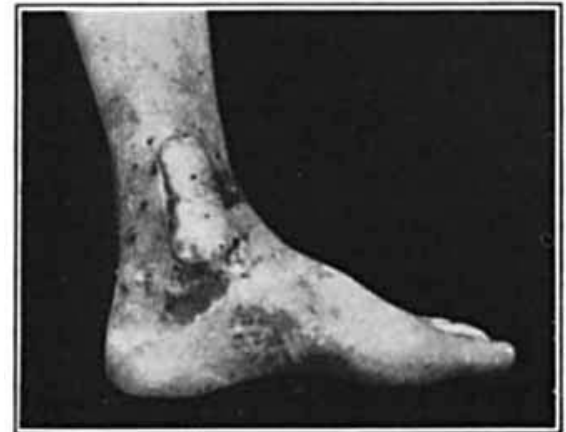

Fic, 333.-Final result of the case shown in Fig. :1:2. The chronic ulcer is completely healed by the

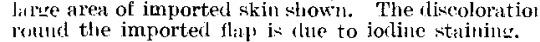
of the tubed-pedicled skin-graft; and that the results obtained by this method warrant its being regarded as in many cases the method of choice, the method that gives promise of the most certain and stable healing. This method ensures the filling in of the tissue gap left after preliminary excision of the unhealed ulcer by flaps of skin brought in from a distancefor example, from the opposite limb, from another segment of the same limb, or from the front of the chest or abdomen. By this method a large area of healthy skin can be imported to the place where it is required, and kept with an independent blood-supply of its own for as long as may be necessary for it to unite with its new bed. Moreover, the flap can be chosen from a part where there exists so great a redundance of skin as to allow of the complete closure of the defect resulting from cutting the flap and its pedicle, either by immediate aseptic suture or by suture assisted by a small amount of aseptic Wolfe grafting. 


\section{THE 'TUBE SKIN-FLAP IN PLASTIC SURGERY}

The advantages of this method may be summarized :-

1. The graft is taken from a place where it can be easily spared.

2. A far larger graft can be cut, transplanted, and maintained alive than any simple pedicled graft obtained locally.

3. Such a graft possesses through its tubed pedicle an independent blood-supply that can be maintained over an almost indefinite surface.

4. The gap left by cutting the flap and its pedicle can be closed aseptically and its healing completed before this area is approximated or in any way connected with the infected discharging surface on to which the flap is to be grafted.

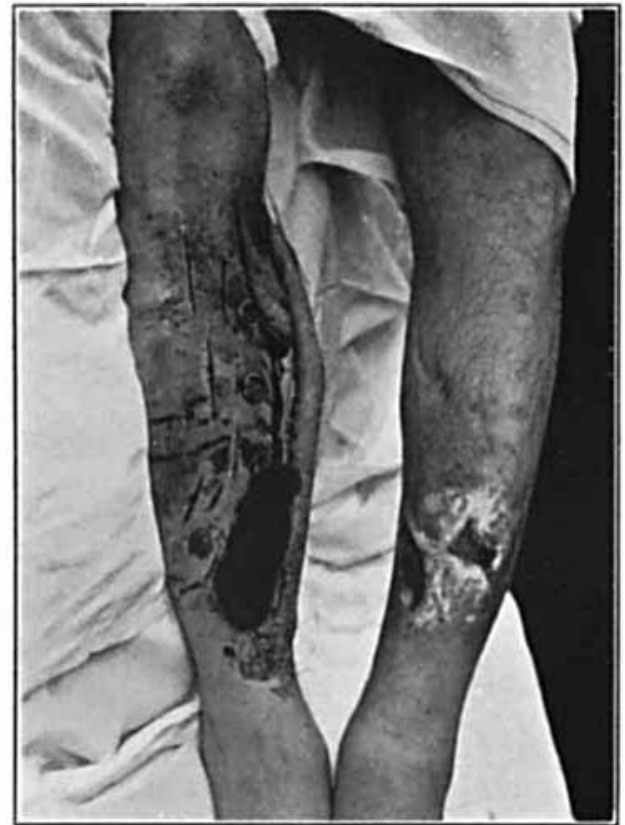

FIG, 334

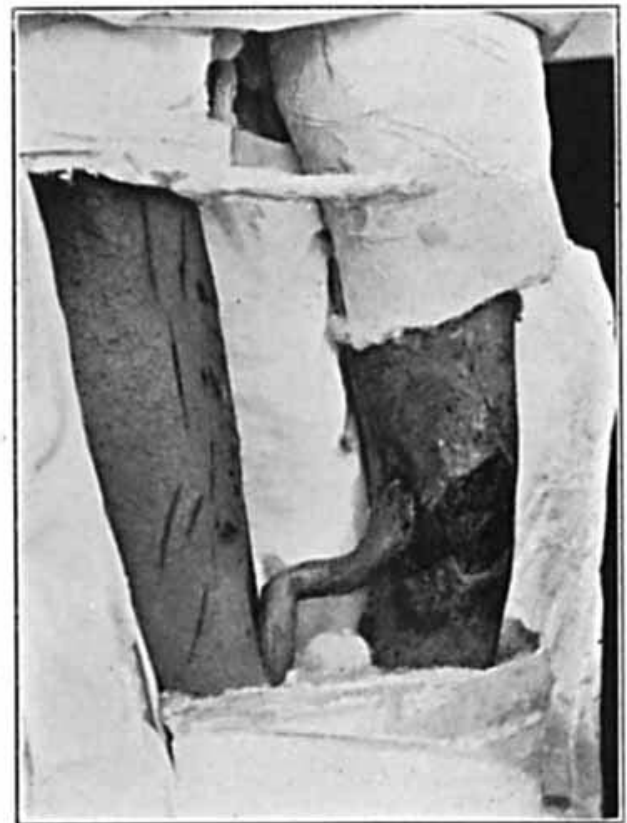

FIG. 335 ,

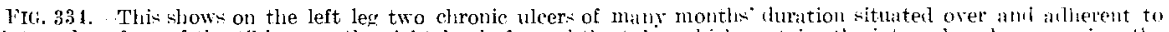
the internal surface of the tibia; on the right les ik formed the tube, which contains the internal saphenous vein: the milde part of the gap left after cutting the tube has been closed by suture with button to assist in bearing the teision, and in addition many tension cuts have been made through the skin on either side of the suture line. in order to

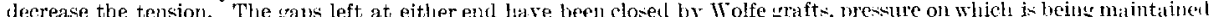
by rauze pacis.

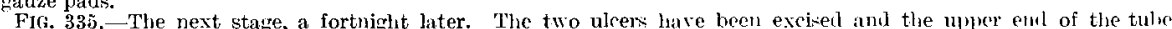

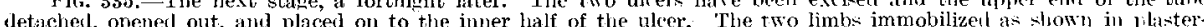
of-Paris, side by side. Three weeks in this position was sufficient for the oridted end to gain al bloon!-xulpuly sufticient to nourish the whole tube. (See Fig. 336.)

5. The length of the tubed pedicle allows the distance between the source of the transplant and its new bed to be sufficient to make the position of retention of the limb as comfortable as possible for the patient and much more tolerable than if the two parts of the limb were to be closely approximated.

6. The final pathological result approaches most nearly to the ideal one formulated above.

This method of importing flaps of full thickness of healthy tissue is very useful in replacing, by such normal skin, areas of scar skin and scar tissue which in the neighbourhood of joints are producing a deformity or are causing a limitation of the range of movement. Especially is it to be used in contractions of the fingers and hand after burns, septic infections, etc. 
The Technique of the Tube-pedicled Method of Skin Implantation as adapted to the Treatment of Chronic Ulcers of the Limbs.- The essential steps in the carrying out of the skin transplantation are as follows :-

1. The formation of the skin-flap with its tubed pedicle.

2. The preparation of the surface of the ulcer for the reception of the flap.

3. The implantation of the skin-flap, connected through its pedicle with an independent source of blood-supply.

4. The maintaining of close contact between the under surface of the flap and the granulating surface of the ulcer until they unite by secondary adhesion of their granulating surfaces.

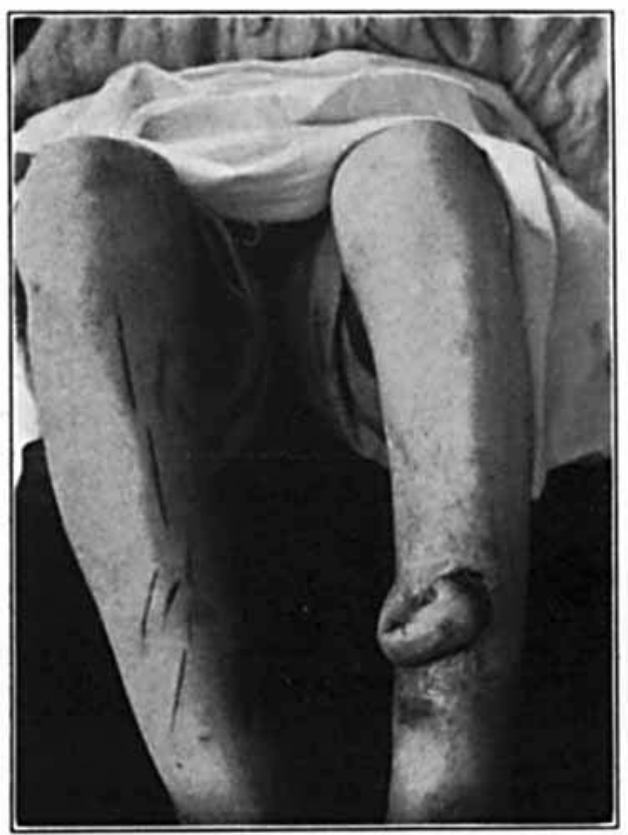

EI(:. 336 .

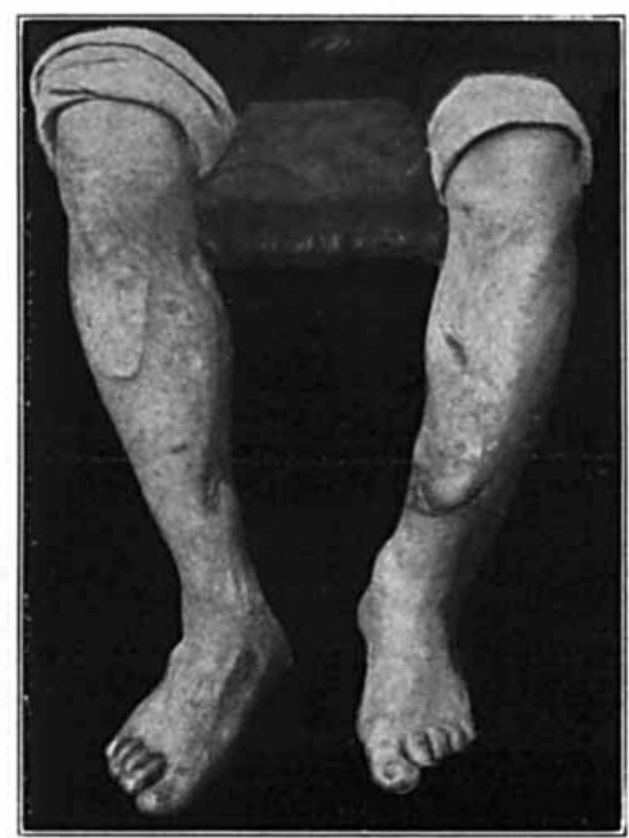

FIG. $33 i$.

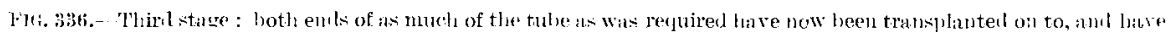

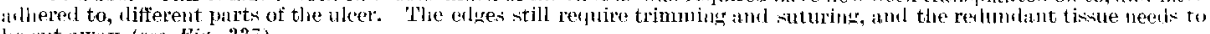
he cut away (sre Fig. 337 ).

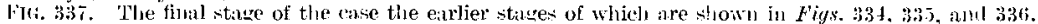

5. The division of the pedicle and the close adaptation of skin-flap to the edges of the ulcer, so that as small an area as possible of raw surface is left to become covered with thin epithelial 'skin scar'.

The duration of the whole process varies in different cases; in the simplest the transplantation takes about six weeks to accomplish, and requires the performance of at least three separate operative stages, each of which is preceded and followed by a period of preparation and waiting. More difficult cases take about three months, and the number of operations that will be required may be as many as six or eight-none of them of course being severe.

The First Pre-operative Period.-It is important that the ulcer and the surrounding skin should be in as healthy a condition as possible before attempting the first stages in the skin transplanting; with this end in view the wound should be treated on general surgical lines with antiseptics, ointments, etc., in order to reduce to a minimum bacterial activity and inflammation in and around the ulcer; it is also important that the surface 


\section{THE TUBE SKIN-FLAP IN PLASTIC SURGERY}

should be made as dry as possible ; to effect this nothing seems to equal the daily exposure of the wound to the sunlight.

Before the first operation is attempted, its details should be carefully worked out and rehearsed. The site from which it is proposed to obtain the transplant has to be carefully chosen, and the direction and length of the flap and its pedicle determined.

In most cases the writer has made use of the following sites :-

1. For ulcers of the foot or about the ankle, the skin of the opposite thigh or the skin of the buttock of the same side.

2. For ulcers about the calf and knee, the skin of the inner side of the opposite leg about the same level.

3. For ulcers of the thigh, the skin of the inner side of the opposite thigh.

4. For ulcers of the upper limb, the skin of the front of the chest or abdomen.

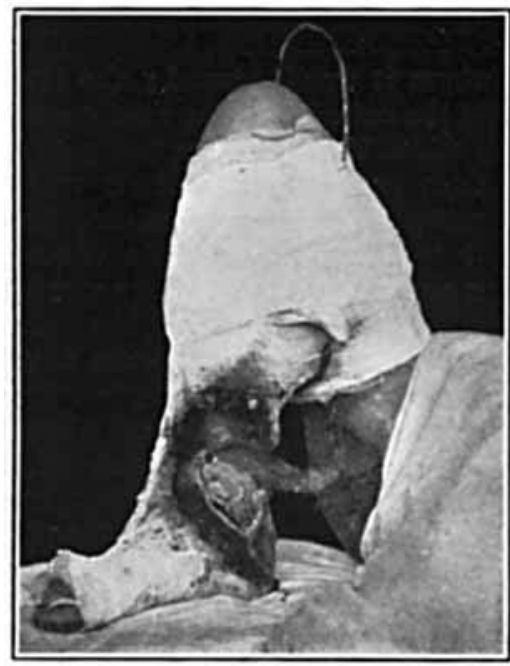

FIT. 338.

As regards the direction of the tubed pedicle: where this is to be cut from the skin of the inner ide of the leg or thigh, the writer has found it advantageous to include in the pedicle the

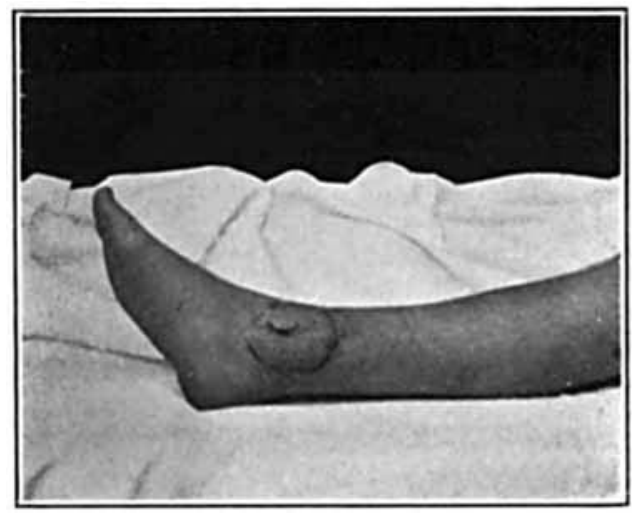

FIC. 339.

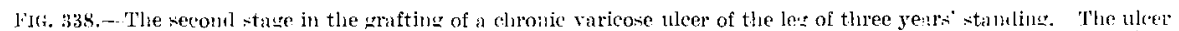
han been excised, ant a lanre skin tube formed on the buttock of the same silfe, three weeks before at the first oneration It this secoml operation one end of this tube had heen cut, and transplanted on to the upper half of this exciken ulcer, the jimb being then immobilized in the position sliown, for a month, when the other ent of the tube was letached from the limb bet

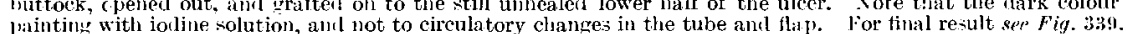
aintine with iodine solution, and not to circulatory changes in the tube and flap. For final result ssp Fig. 339?. and suturing of contizuous enlires. This has left an elevated area of liealthy skin ju place of the uleer : experience law shown that in time the imported llap sinks to the same level as the rest of the skin of the limb.

internal saphenous vein; elsewhere one must be guided by the known anatomical facts regarding the blood-supply of the skin. An excellent account of this subject, worked out for the needs of plastic surgery, was given in an article by Pieri in La Chimurgir degli Organi di Movimento, 1918, vol. ii, Fasc. 2, April. As regards the length, this must be calculated beforehand with the limb fixed in the intended position.

The First operation.-This includes (1) An aseptic stage; and (2) $A$ septic stage.

1. The Aseptic Stage. - This consists of the cutting of a long flap of skin of the determined length and direction, and its tubulization. The gap left after this step has been taken must now be closed. Except for a triangular piece at each end where the flap widens out, this can be done almost always by undercutting and suturing with tension sutures. The two triangular raw areas should be grafted with Wolfe grafts, which are sewn in place and kept pressed down on to their beds by means of pads of gauze placed between them and the attached ends of the tube.

2. The Septic Strage.-The surgeon then proceeds to the complete excision of the 
ulcer and its surrounding mass of scar tissue, including the circumference of thin epithelial skin scar.

First period of post-operative treatment.-During this period of fourteen days the excised surface that now represents the ulcer should be daily dressed and kept as clean and dry as possible.

For twenty-four hours previous to the next operation a tight ligature should be tied so as to strangulate the blood-supply through that end of the skin tube which it is intended to sever on the morrow. This renders the tube dependent on one source of blood-supply, that from the other end only. It also serves to test whether the tube has as yet a sufficiently rich blood-supply to survive this reduction in the number of its sources; if after an hour or two part of the tube looks pale and becomes cold, then the ligature can be removed and the next operative stage postponed until such time as this ligature test proves satisfactorily that it is safe to cut off the blood-supply from this end.

The Second Operation.- -

1. The tube should be cut through at the point where it was ligatured ; the bloodflow through the tube should now be examined; should the cut edge of the tube continue to ooze then it is likely to survive; in the rare cases in which it simply becomes pale and

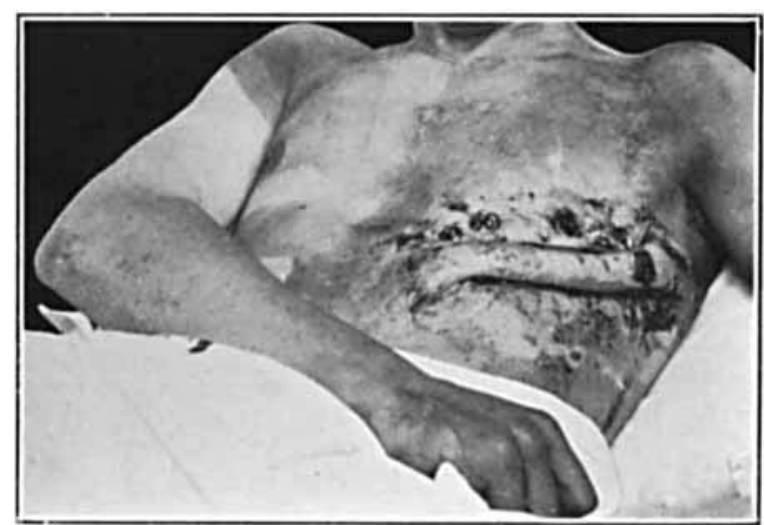

FIf. 3411.-- Ihe first stare in a cke of i nporting skin from the chest by mears of the tubed pedicleal flap to rethace the chronic ulcer surtommleil by scar on the dorsum of the liand. The second stage will be similar to that shown in Fig. 330 . does not ooze it will be wise to postpone opening it out and fixing it to the surface of the ulcer for a day or two, to test its viability.

2. The free cnd of the tube is now opened out, but only a sufficient area to furnish a good broad surface for apposition and adhesion to the granulating surface of the ulcer; unless the ulcer is a small one there need be no attempt at this stage to fill the defect completely with the imported skin; the free edges of this part of the flap are then sutured to the contiguous edges of the ulcer and the two surfaces maintained in contact by means of firm pressure by a pad and bandage.

3. The limb or limbs must now be immobilized in the required position - usually by plaster-of-Paris-so that no involuntary movement of the patient may detach the flap from contact with the surface to which it is being grafted. It is essential, wherever one limb or segment of a limb is superimposed upon another, that the one should not rest actually in contact with the other; otherwise a pressure sore will inevitably result.

Second period of post-operative treatment.- The most important indication for treatment now is the maintenance by pressure of absolute contact between the two surfaces. the deep surface of the flap and the surface of the ulcer; the sooner union has been obtained between them, the shorter will be the period of fixation in a not too comfortable position for the patient, and the sooner will it be possible to divide the pedicle and proceed to the utilization of the pedicle itself for the covering in of the rest of the ulcerated surface.

When it is considered that the time has come for the division of the pedicle, and that the tube has now a sufficient blood-supply from its union with the ulcer, it can be put through a ligature test similar to that described above for the twenty-four hours preceding the next operation. 


\section{THE TUBE SKIN-FLAP IN PLASTIC SURGERY 333}

The Third Operation.-The pedicle is divided and the limbs are freed from the retention apparatus ; the cut end of the pedicle should now bleed quite freely and continue so to bleed; otherwise it will be well to wait a few days before opening out an inch or two of this end of the tube and implanting it on another part of the surface of the uleer and suturing it into position and exerting pressure on it exactly as was done in the case of the first piece transplanted.

The third period of post-operative treatment.--The pressure on this part of the flap is maintained in the same way until it, too, is firmly united in position; the imported tube should now somewhat resemble the handle of a Gladstone bag, the two broad flat ends adherent to the ulcer united by the still tubulized middle portion of the pedicle.

The Fourth Operation.- This consists in adapting this central part of the tubulized skin-flap to whatever surface of the ulcer is still raw and uncovered by imported tissue; the redundant parts are trimmed away.

The fourth post-operative period is concerned with the maintaining in apposition such of these parts as have still to unite with the ulcer. 